\title{
NEW MATRIXES TO DIAGNOSE AETHINA TUMIDA PRESENCE AT APIARY LEVEL
}

\author{
Antonella Cersini ${ }^{1}$ \\ Marco Pietropaoli ${ }^{1 \star}$ \\ Gabriele Pietrella ${ }^{1}$ \\ Jorge Rivera-Gomis ${ }^{1}$ \\ Giovanni Federico ${ }^{2}$ \\ Silvia Tofani ${ }^{1}$ \\ Raffaella Conti ${ }^{1}$ \\ Roberta C. Rubino' \\ Camilla Di Ruggiero ${ }^{1}$ \\ Giovanni Formato ${ }^{1}$ \\ "Istituto Zooprofilattico Sperimentale del Lazio e della Toscana "M. Aleandri", Rome, \\ Italy \\ 2Istituto Zooprofilattico Sperimentale del Mezzogiorno, Loc. Catona, Reggio \\ Calabria, Italy \\ *corresponding author: marco.pietropaoli@izslt.it \\ Received: 24 February 2021; accepted: 17 June 202
}

Abstract

Aethina tumida (Coleoptera: Nitidulidae - Small Hive Beetle - SHB), is a parasite of honey bee colonies that causes the notifiable disease called aethinosis. In 2014, SHB was detected in Southern Italy, where it is still present (Calabria region). As part of surveillance activities, official diagnosis of the disease is performed by veterinary services via visual inspection of single hives in the apiaries. New outbreaks can be eradicated and the spread of SHBs limited by early detection of new introductions. We report an alternative protocol for the diagnosis of SHB through swabs and hive debris analysis by PCR. This was tested in three apiaries through the evaluation of different SHB infestation levels with a hive inspection method. This approach for sampling, followed by biomolecular methods, was fast and useful in unfavorable conditions (bad weather, aggressiveness, robbing), could be integrated in the official diagnosis procedures and may act as pre-clinic indicator.

Keywords: Aethina tumida, hive debris, swab, PCR

\section{INTRODUCTION}

Aethina tumida (Coleoptera: Nitidulidae - Small Hive Beetle - SHB) is an invasive honey bee pest native to Sub-Saharan Africa that has spread to all continents except for Antarctica in the last twenty-five years (Neumann et al., 2016). In southern Italy's Calabria region, SHBs have been found in 136 apiaries since September 2014 until December 2016 (Rivera-Gomis et al., 2017) and surveillance activities are still being performed by veterinary services via inspection of single hives in the apiaries.

Between 2016 and 2017, during inspection visits during three outbreaks in the same region, colonies of three different apiaries were visually inspected (Neumann et al., 2013) to verify SHB presence. After quantification, samples of debris from screened hive bottom boards (Cepero et al., 2014) or swabs from hive bottom and frames were collected to test alternative protocols for early diagnosis.

In order to gather swab samples from hive bottom boards, first the hive was opened, and next three lateral frames were removed. A sterile swab was moistened in $3 \mathrm{~mL}$ of PBS medium for few seconds and then rubbed with slight pressure and rotation, along all the lateral angle (Fig. 1 (1)) and the first $3 \mathrm{~cm}$ of the rear angle (Fig. 1 (2)), across the surface of the 
lateral part of the bottom of the hive (Fig. 1 (3)) and the lower half of the lateral wall (Fig. 1 (4)) and its angles with the front and back walls (Fig. 1 (5) and (6)). A total surface of $895.5 \mathrm{~cm}^{2}$ was sampled.

The swab sampling procedure for the frames was performed through the choosing of the outer frame on the right of the hive, humidifying a sterile swab in $1 \mathrm{~mL}$ of PBS medium for three seconds and rubbing and rotating it on the full top bar (Fig. 1 (7)). A total surface of $2.5 \times 47$ $\mathrm{cm}^{2}$ was sampled.

Swab sampling was performed in corners and inner side of the walls of the hive, behind dividers and peripheral areas of the hive where SHB would more likely be found (Rivera-Gomis et al., 2017). All swabs were transported at a refrigerated temperature on ice and preserved at $-20^{\circ} \mathrm{C}$ until processing.

In order to collect hive debris, a metal inspection panel was inserted into screened bottom boards one week before sampling. $5 \mathrm{~g}$ of debris were sampled with the use of a sterilized spoon moved in an asterisk-shaped pattern (Fig. 1 (8)). Samples were transported on ice at refrigerated temperature and conserved at $-20^{\circ} \mathrm{C}$ until processing.

In the laboratory, samples were diluted in $10 \mathrm{~mL}$ of PBS $1 \mathrm{X}$ and incubated for two hours at $37^{\circ} \mathrm{C}$ with agitation. $2 \mathrm{~mL}$ of hive debris were used for the DNA extraction with the NucleoSpin Tissue (Macherey-Nagel, Düren, Germany) following manufacturer instructions. One $\mathrm{ml}$ from each swab was vortexed and $200 \mu$ of solution was used for DNA extraction as above.

Molecular analysis was performed as described by Ward et al. (2007) and the LOD was established in vitro for both debris (from $1.81 \times 12^{2}$ to 5 copy/1 g) and swabs (from $1.81 \times 12^{2}$ to 5 copy/200 $\mu$ ). A 109 bp fragment of COI gene from SHBs was amplified through real time PCR with the use of the TaqMan universal PCR Master Mix kit (Applied Biosystems, Foster City, CA, USA). Primers and probe concentrations were $600 \mathrm{nM}$ and $300 \mathrm{nM}$ respectively per 25 $\mu \mathrm{l}$ reaction. Plates were cycled at the following conditions: $50^{\circ} \mathrm{C}$ for $2 \mathrm{~min}, 95^{\circ} \mathrm{C}$ for $10 \mathrm{~min}$ and 50 cycles of $95^{\circ} \mathrm{C}$ for $15 \mathrm{sec}, 52^{\circ} \mathrm{C}$ for $15 \mathrm{sec}$ and $55^{\circ} \mathrm{C}$ for $30 \mathrm{sec}$.

Positive samples were further confirmed through Sanger sequencing of a 800 bp region coding for the $\mathrm{COI}$ gene as described by Evans et al. (2000). Moreover, a second pair of oligonucleotides were designed inhouse and used for further confirmation. Briefly, fifteen COl sequences from a public
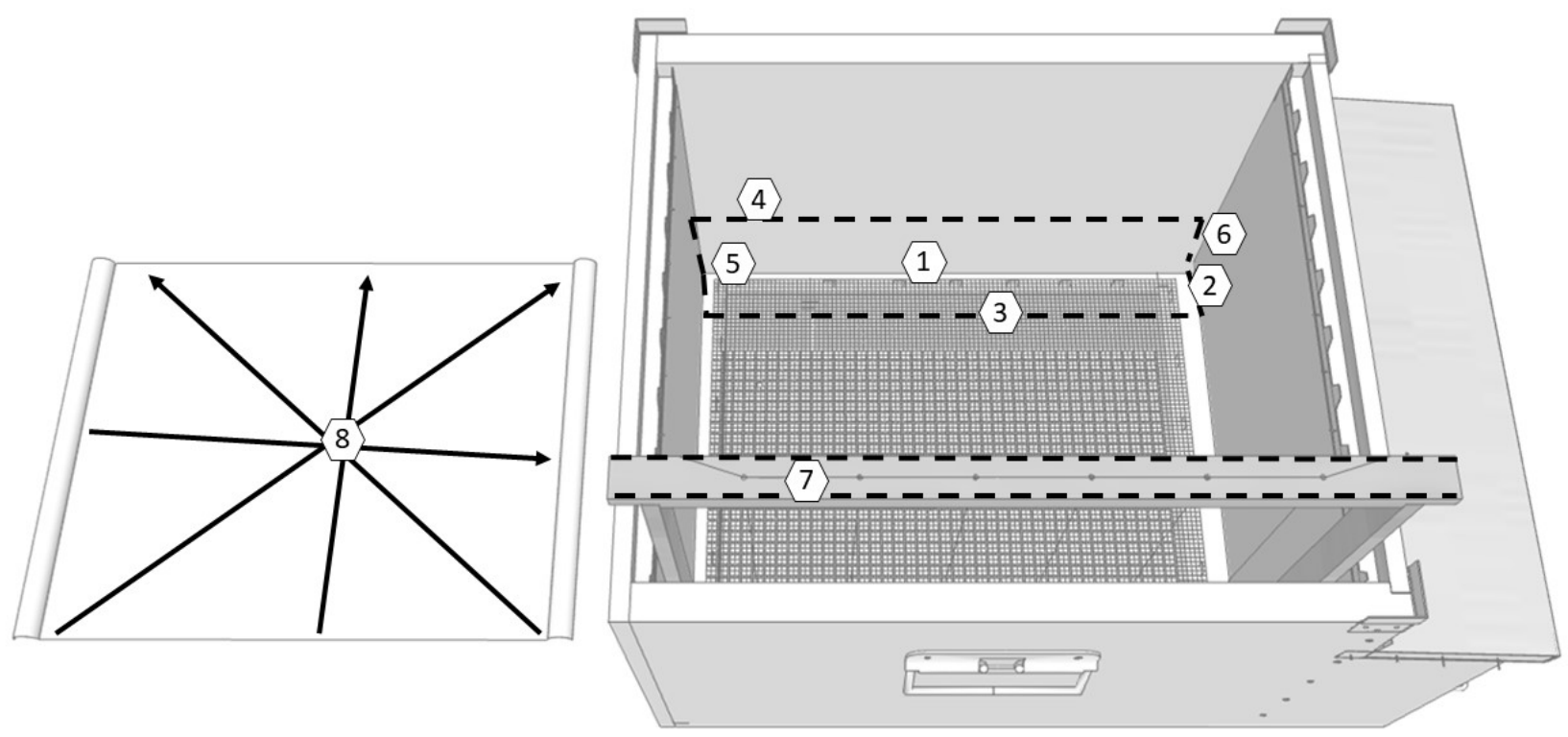

Fig. 1. Selected area for debris and swab samplings: lateral angle (1), first $3 \mathrm{~cm}$ of the rear angle (2), the surface of the lateral part of the bottom of the hive (3), lower half of the lateral wall (4), angles of the lateral wall with the front and back walls (5 and 6). 


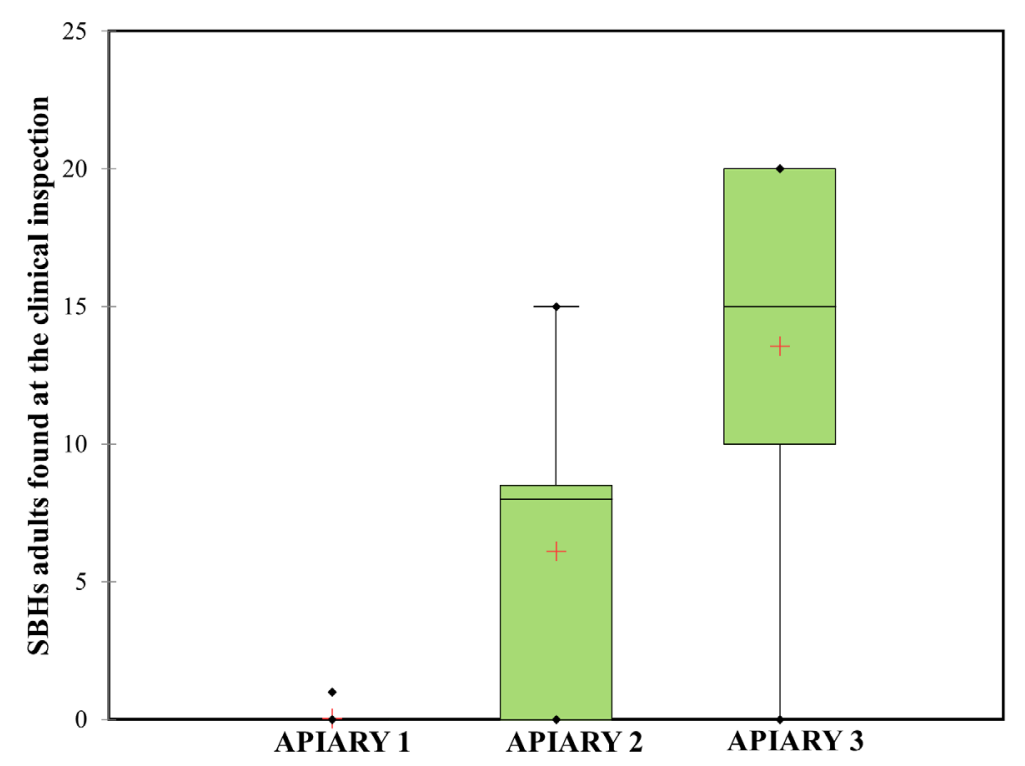

Fig. 2. SHB adults in the three apiaries found at the inspection visit. Minimums and maximums as points, means as crosses, first and third quartiles as boxes, medians as lines.

database were subjected to multiple alignment with the Geneious 9.1.3 software and the oligonucleotides were designed (F-AETHI 5'-TGCGACCCTCAGGCATAACCT-3' and R-AETHI: 5'-TGGGAATCATTGAACAATCCGGCT-3').

To ensure the absence of an inhibited amplification reaction, protocol accuracy was determined from DNA extracted directly from negative field samples made positive with the real time PCR target for the SHB COI gene. A Mann-Whitney test was used to compare the infestation levels of apiaries. The number of hives positive to visual inspection were $1.9 \%$ $(1 / 51)$ in apiary $1,75.0 \%(6 / 8)$ in apiary 2 and $100 \%(7 / 7)$ in apiary 3 . The mean number of adult SHBs found in apiaries was statistically different (Mann-Whitney test: $p<0.0001$ ) in the three apiaries: $0.04 \pm 0.20$ in apiary $1 ; 6.13 \pm 5.57$ in apiary 2 and $13.57 \pm 7.48$ in apiary 3 (Fig. 2).

The number of samples collected in each apiary were related to the number of hives available in apiaries and the presence of screened bottom boards. Fifty-one debris samples, fifty-one swab samples from frames and fifty-one swab samples from hive bottom boards were collected from apiary 1. Hives in apiaries 2 and 3 had solid bottom boards; in apiary 2 four swab samples were collected from frames and three swab samples from hive bottoms, while in apiary 3 six swab samples were collected from hive bottom boards.

In apiary 1, with a very low infestation level at the inspection visit, three samples of debris were positive via PCR analysis (5.8\%) while none of the swab samples were in apiary 2 with a medium infestation level, $50 \%$ of swabs from frames and $37.5 \%$ of swabs from hive bottoms were positive via PCR. In apiary 3, with a very high infestation level, $85.7 \%$ of swab samples from hive bottom were positive to PCR.

The sequenced samples showed a sequence identity and a query cover of $99 \%$ to AfricCam3 sequences, belonging to clade $B$, cluster $B 1$ (HM056044.1). The sampling and biomolecular methods presented here are fast, easy to apply and could be integrated to contingency plans or used in combination with the standard inspection of the colonies reducing costs and resources.

Moreover, debris samples can be taken even in unfavorable conditions that limit hive inspection including bad weather, aggressiveness and robbing. This method could detect conditions in which SHB is not present during the visit of the colony but nevertheless present in the аріагу. Finally, because the PCR detection sensitivity and specificity for the SHBs present in Italy are high (specificity $=100 \%$, sensibility >99\%) (Granato et al., 2017; Mutinelli et al., 2015), debris samples analysis can be useful for routine 
surveillance in high-risk areas at early stages of infestation, acting as a pre-clinic indicator when SHB adults presence is not massive.

So far, there has been no specific literature regarding SHB nucleic acid extraction from swabs. This method should be further studied through the comparison of its detection efficacy on other parts of the hive.

\section{ACKNOWLEDGEMENTS}

The authors wish to thank Benjamin Dainat, Paolo Silacci and the Secretary-General of Apimondia Riccardo Jannoni-Sebastianini for their kind contributions and comments.

\section{REFERENCES}

Cepero, A., Higes, M., Martínez-Salvador, A., Meana, A., Martín-Hernández, R. (2014). A two year national surveillance for Aethina tumida reflects its absence in Spain. BMC Research Notes, 71). https://doi. org/10.1186/1756-0500-7-878

Evans,J.D., Pettis,J. S., Shimanuki, H. (2000). Mitochondrial DNA relationships in an emergent pest of honey bees: Aethina tumida (Coleoptera: Nitidulidae) from the United States and Africa. Annals of the Entomological Society of America, 93(3), 415-420. https:/l doi.org/10.1603/0013-8746(2000)093[0415:MDRI AE]2.0.CO;2

Granato, A., Zecchin, B., Baratto, C., Duquesne, V., Negrisolo, E., Chauzat, M. P., ... Mutinelli, F. (2017). Introduction of Aethina tumida (Coleoptera: Nitidulidae) in the regions of Calabria and Sicily (southern Italy). Apidologie, 48(2), 194-203. https://doi.org/10.1007/ s13592-016-0465-3

Mutinelli, F., Federico, G., Carlin, S., Montarsi, F., Audisio, P. (2015). Preliminary investigation on other Nitidulidae beetles species occurring on rotten fruit in Reggio Calabria province (South-western Italy) infested with small hive beetle (Aethina tumida). Journal of Apicultural Research, 54(3), 233-235. https://doi.or g/10.1080/00218839.2016.1142733
Neumann, P., Evans, J.D., Pettis, J.S., Pirk, C.W.W., Schäfer, M.O., Tanner, G., Ellis, J.D. (2013). Standard methods for small hive beetle research. V. Dietemann; J.D. Ellis, P. Neumann (Eds) The COLOSS BEEBOOK, Volume II: standard methods for Apis mellifera pest and pathogen research. Journal of Apicultural Research 52(4), 32 pp. http:///dx.doi.org/10.3896//BRA.1.52.4.19

Neumann, P., Pettis, J. S., Schäfer, M. O. (2016). Quo vadis Aethina tumida? Biology and control of small hive beetles. Apidologie, 473), 427-466.

Rivera-Gomis, J., Gregorc, A., Ponti, A. M., Artese, F., Zowitsky, G., Formato, G. (2017). Monitoring of small hive beetle (Aethina tumida murray) in Calabria (Italy) from 2014 to 2016: Practical identification methods. Journal of Apicultural Science, 67(2), 257262. https://doi.org/10.1515/JAS-2017-0022

Ward, L., Brown, M., Neumann, P., Wilkins, S., Pettis, J., Boonham, N. (2007). A DNA method for screening hive debris for the presence of small hive beetle ( $A e$ thina tumida). Apidologie, 38(3), 272-280. https:// doi.org/10.1051/apido:2007004 